\title{
Virgin Olive Oils
}

\section{Priya Shetty $\mathrm{K}^{*}$}

Department of Food Science and Technology, School of Life Sciences, Pondicherry University, Pondicherry, India

*Corresponding author: Priya SK, Department of Food Science and Technology, School of Life Sciences, Pondicherry University, Pondicherry, India, Tel: 0413265 5179; E-mail: priyashetty.kumar@pondiuni.edu.in

Received date: March 04, 2017, Accepted date: March 15, 2017, Published date: March 23, 2017

Copyright: $\odot 2017$ Priya SK. This is an open-access article distributed under the terms of the Creative Commons Attribution License, which permits unrestricted use, distribution, and reproduction in any medium, provided the original author and source are credited.

\begin{abstract}
Virgin means that the oil was created by merely pressing olives. It did not endure any of the economic processes accustomed build refined oils like canola, sunflower, soybean and also the lower grades of oil labeled Pure, Light, and easily Olive Oil. Virgin olive oils that haven't any style defects and pass strict tests in terms of chemistry will be labeled Extra Virgin. Virgin olive oils that have modest style defects and meets somewhat less strict chemical parameters square measure labeled Virgin. Sadly, you do not see Virgin oils purchasable as a result of too usually producer's market Virgin oils as Extra Virgin to command higher costs. Till standards social control catches up with apply, real Extra Virgin is arduous to return.
\end{abstract}

\section{Introduction}

The olive tree is a standout amongst the most essential products in the Mediterranean nations. The sources of the development of the olive tree lie established in legend and custom. It most likely began around 5000-6000 years back inside a wide segment of land by the eastern Mediterranean ocean and in the adjoining zones containing Asia minor, some portion of India, Africa, and Europe. Others trust that the olive tree started from Africa. This is the place olive trees were initially developed methodically, and from where they spread to Cyprus, Morocco, Algeria, Tunisia and to western places by the Phoenicians.

Virgin olive oil (VOO), superb common nourishment, is acquired from olive organic product (Olea European L.) by mechanical or physical methods. Its creation shifts broadly, contingent upon natural product assortment, level of organic product readiness, ecological conditions, developing area, and procedures of preparing and capacity [1]. VOO has demonstrated a high imperviousness to oxidative crumbling because of unsaturated fat organization and phenolic cancer prevention agents.

As they are the slightest prepared types of olive oil, additional virgin or VOOs have more monounsaturated unsaturated fats than other olive oils. No other normally created oil has as a lot of monounsaturated as olive oil, for the most part oleic corrosive, and these higher extents of monounsaturated fats in the eating routine are connected with a lessening in the danger of coronary illness. VOO likewise contain more phenols, for example, oleuropein subsidiaries and hydroxytyrosol, and cell reinforcements, for example, vitamin E and carotenoids, that may help keep the oxidation of LDL particles, giving medical advantages to the heart, for example, good consequences for cholesterol direction, and anti-inflammatory, antithrombotic, antihypertensive and in addition vasodilator impacts both in creatures and in people [2,3]. Another medical advantage of olive oil is by all accounts its property to dislodge omega- 6 unsaturated fats, while not having any effect on omega-3 unsaturated fats. Thusly, olive oil constructs a more sound harmony between omega- 6 and omega-3 fats.
As a rule quality parameters change when the oil achieves the shopper. Olive oil is powerless to both hydrolytic and oxidative response that can antagonistically influence oil quality parameters [4]. For example, an expansion in PV, K232 and K270 qualities and advancement or loss of certain unstable mixes is exceptionally regular amongst extraction and utilization. The nearness or nonattendance of specific unpredictable mixes may likewise be a decent marker of olive oil quality changes.

A few variables are known to influence the quantitative profile of olive organic products. Among these components, the level of readiness, the geographic starting point and the way of the cultivar are absolutely those that impact the creation [5]. A few reviews were at that point distributed concerning the impact of these components on some French, Spanish, Italian, Portuguese and Tunisian cultivars.

In this review, some Egyptian VOOs have been examined with a specific end goal to assess their levels of value. For this reason, the substance structure, the unstable mixes and their sensorial investigation were resolved [6].

The composition of fatty acids:

Unsaturated fat synthesis is a basic part of the subjective appraisal of olive oil. Unsaturated Fatty Acids (UFA) are of incredible significance in light of their dietary ramifications and impact on the oxidative solidness of oils.

The information uncovered that the recognized unsaturated fats in every one of the specimens were run of the mill of olive oil and comprised of meristic corrosive (C14:0), palmitic corrosive (C16:0), palmitoleic acid (C16:1), stearic corrosive (C18:0), oleic corrosive (C18:1), linoleic corrosive (C18:2), linoleic corrosive (C18:3), archaic corrosive (C20:0), eicosanoid corrosive (C20:1), behenic corrosive (C22:0) and lignoceric corrosive (C24:0). These unsaturated fats have a vital impact in the tactile portrayal of olive oil. It can be demonstrates that in every one of the examples, the oleic corrosive was dependably the most inexhaustible unsaturated fat, speaking to $67 \mathrm{~g}$ for each $100 \mathrm{~g}$ of the aggregate unsaturated fat piece at any rate, with the exception of Arequipa test where the rate esteem was just $44.00 \pm 1.65 \mathrm{~g}$ for each $100 \mathrm{~g}$, albeit different creators have discovered diverse qualities that 
Page 2 of 2

vary essentially from what we have discovered. Palmitic corrosive was likewise the most predominant immersed unsaturated fat (SFA) in all examples explored. The substance fluctuated between $11.69 \pm 0.52$ for Maraqi oil and $21.36 \pm 0.98 \mathrm{~g}$ for every $100 \mathrm{~g}$ for Arequipa oil. Linoleic corrosive is a di unsaturated fat; when present in outstanding amounts, it can add to the oxidation of olive oil amid capacity. The diagnostic outcomes demonstrated that the substance of this corrosive differed between $8.87 \pm 0.69$ and $28.02 \pm 1.38 \mathrm{~g}$ for every $100 \mathrm{~g}$. These outcomes concur with those acquired by different creators. The unsaturated fat piece of the concentrated olive oils conforms to the necessities of the IOC exchange standard, with the exception of Arequipa olive oil.

The examples of Maraqi and Wattagen demonstrated the most reduced aggregate SFA $(14.83 \pm 0.20$ and $14.81 \pm 0.20$, separately and the most noteworthy aggregate UFA $(85.08 \pm 1.13$ and $85.12 \pm 1.14$, individually), while tests of Arequipa demonstrated the most astounding aggregate SFA (23.28 $\pm 0.36 \mathrm{~g}$ for each $100 \mathrm{~g})$ and the least aggregate UFA $(76.58 \pm 0.74 \mathrm{~g}$ for every $100 \mathrm{~g})$ when contrasted with alternate VOOs.

The proportions between the aggregate SFA to aggregate UFA again affirmed the above outcomes, that the oils from Maraqi and Wattagen cultivars had the most reduced proportions $(0.17 \pm 0.10)$. Then again, Arequipa oil had the most noteworthy proportion $(0.30 \pm 0.20)$.
When all is said in done, quality olive oils ought to demonstrate a rate substance of oleic corrosive higher than $73 \%$, a rate substance of linoleic corrosive lower than $10 \%$ and a proportion of these two acids more noteworthy than 7 . From the information acquired, these qualities are completely regarded by the oils from Siwa desert garden.

\section{References}

1. Psomiadou E, Tsimidou M, Boskou D (2000). A-tocopherol content of Greek virgin olive oils. J Agric Food Chem 48: 1770-1775.

2. IOC (2006) Trade standard applying to olive oils and olive pomace oils.

3. Dhifi W, Khedher MB, Kchouk ME, Marzouk B (2006) Qualitative and quantitative of the aromas and polyphenols of some Tunisian olive oils. Olivae 105: 36-42.

4. Cavaliere B, De Nino A, Hayet F, Lazez A. 2007. A metabolomic approach to the evaluation of the origin of extra virgin olive oil: a convenient statistical treatment of mass spectrometric analytical data. J Agric Food Chem.

5. Boskou D, Blekas G, Tsimidou M (2006) Olive oil composition.

6. Morales MT, Luna G, Aparicio R (2008) Comparative study of virgin olive oil sensory defects. Food Chem 91: 293-301. 